\title{
Challenging the Teaching Excellence Framework
}

\section{A book review of A. French, and K. Carruthers Thomas (eds) (2020) Challenging the Teaching Excellence Framework: diversity deficits in higher education evaluations. Bingley: Emerald Publishing.}

\author{
Dr. Teresa De Fazio \\ Cultural Diversity Manager, Victoria University
}

Keywords: Teaching Excellence Framework (TEF); diversity; higher education.

\section{Overview}

The Teaching Excellence Framework (TEF) is controversial for the way it interprets and sets out to reward excellence in higher education. The debate on the implications of the Framework for the UK higher education environment is rich and complex as it necessitates an exploration of higher education in terms of its purpose and its stakeholders.

The text details the contextual background to the TEF and the underlying drivers that contributed to its development and adoption, namely, neoliberal factors such as commercialisation, globalisation and expectations around quality assurance. Further, the text provides excellent interdisciplinary discussions into various aspects of how students and staff maybe impacted by the Framework. This review will provide an overview of the contributions and the arguments presented.

Whilst specific to the TEF, the discussions in this edited book have broad international appeal and the exploration on the question of excellence and the extent to which it responds to the diversity of its stakeholders is pivotal to the HE sector more broadly. 


\section{Structure and content}

The text is easy to read and reference. The edited text of 235 pages includes seven chapters, one chapter devoted to a single essay. Each essay represents various perspectives on the TEF and includes a useful reference list. The text itself provides a convenient index at the end. The text has a clear layout with each chapter providing a particular focus and the threads of the arguments are brought together by the editors in a "Postscript".

The first chapter by Sanders et al. provides an insightful literature review which maps out the problematic nature of defining excellence and the different levels of engagement by different stakeholders. It presents a model for considering the notions of excellence, namely macro, meso and micro and presents a deep and surface level interpretation of teaching excellence. This essay provides a strong foundation for the next six essays.

The next chapter, again by Sanders et al., examines ways in which excellence is evidenced in higher education and how the concept of 'excellence' is recognised and rewarded. It explores the tension between research and teaching in how each is perceived (the latter being the 'poor cousin' of the former) and the nexus between both in terms of developmental curricular design to support student learning outcomes.

The third chapter by Crockford, takes up the question of awards and provides an insightful SoTL based discussion on checklists and the complexity of measures used. It focuses on how learning and teaching is particularly contextual and sensitive to various dependencies and variables, and how the TEF can therefore, be problematic.

Lawrence et al, in the fourth chapter, provide a discussion of research on the rapport between teachers and students as evidence of excellence. It outlines various barriers to building personal relationships such as unconscious bias and the question of gender pay gaps. The argument is somewhat vague at various points in this essay, however, overall, it does provide the reader with thought-provoking cues to consider.

The next essay (Chapter 5) delves into the question of student evaluations as an 'authoritative source', that is, representing the student voice in the process of evaluating 
the learning experience. The essay points out that the process relies on using the metrics at a general or superficial level, and without a deeper level analysis of result, much of the rich learnings around excellence are overlooked. Further, it notes that students may respond in particular ways that are not open to (respectful of) the diversity of their teacher, for instance, their sexuality, gender, cultural background, etc. This then complicates the data collected.

Bartrum, in chapter six, takes up the discussion and provides an insightful essay using queer theory to analyse the Framework. The premise presents HE as situated in a 'masculinist business ontology' (p. 192) which continues to perpetuate a sense of 'normal'. Queer theory is posited as a way of challenging the status quo, in order to consider teaching and learning from an authentic place of openness and inclusion.

Brogan presents the last essay in which he argues that the quantifiable measures used in the TEF reduce teaching and learning to a 'provider-consumer relationship'. The essay argues that conformity is elicited by the Framework, that is, ensuring that each person remains in their 'proper place' and is required to interact in 'expected ways' (p.208). The essay draws on the work of social theorist Michel de Certau and his call to practice 'wiggery'. In this very clever essay, Brogan takes up this call to teachers to elicit a creative response to resisting the neoliberal TEF framework.

\section{Concluding remarks}

The text questions the interpretation of excellence adopted by the TEF and limitations of how it is measured by the Framework from the perspective of diverse learners and staff. The contributors and editors provide a pivotal text that carefully presents key issues on the TEF, specifically, how it will impact perspectives and experiences of higher education in the UK by not fully addressing or, at times, acknowledging the diversity of students and staff as key stakeholders of the sector itself. It is important reading for anyone who is interested in the issue of excellence in higher education and its measurement, in particular, from the perspective of equity and diversity. 


\section{Author details}

Dr. Teresa De Fazio is the Manager, Cultural Diversity Office at Victoria University (VU) where she has developed and leads VU's Cultural Diversity Strategy. She has over 25 years of experience in tertiary education, with a constant focus on student diversity, interculturality and teacher education. She has developed various initiatives for marginalised groups such as asylum seekers and refugees and is a strong advocate for multiculturalism. She has published various books and journal articles and is a reviewer for several journals. Teresa served as a Commissioner of the Victorian Multicultural Commission in Australia and continues to work closely with communities. Further details: https://www.vu.edu.au/contact-us/teresa-de-fazio 